\title{
Confinement Effects for Lithium Borohydride: Comparing Silica and Carbon Scaffolds
}

\author{
Suwarno, ${ }^{\dagger}$ Peter Ngene, ${ }^{*}, \dagger$ Angeloclaudio Nale, ${ }^{\dagger}$ Tamara M. Eggenhuisen, $^{\dagger}$ Martin Oschatz, ${ }^{\dagger}$ \\ Jan Peter Embs, ${ }^{\ddagger}$ Arndt Remhof, ${ }^{\S}$ and Petra E. de Jongh, ${ }^{*} \dagger \odot$ \\ ${ }^{\dagger}$ Inorganic Chemistry and Catalysis, Debye Institute for Nanomaterials Science, Utrecht University, Universiteitsweg 99,3584 CG \\ Utrecht, The Netherlands \\ ${ }^{\ddagger}$ Laboratory for Neutron Scattering, Paul Scherrer Institute, CH-5232 Villigen PSI, Switzerland \\ ${ }^{\S}$ Materials for Energy Conversion, Swiss Federal Institute for Materials Science and Technology, Empa, CH-8600 Dübendorf, \\ Switzerland
}

\section{Supporting Information}

ABSTRACT: $\mathrm{LiBH}_{4}$ is a promising material for hydrogen storage and as a solidstate electrolyte for $\mathrm{Li}$ ion batteries. Confining $\mathrm{LiBH}_{4}$ in porous scaffolds improves its hydrogen desorption kinetics, reversibility, and $\mathrm{Li}^{+}$conductivity, but little is known about the influence of the chemical nature of the scaffold. Here, quasielastic neutron scattering and calorimetric measurements were used to study support effects for $\mathrm{LiBH}_{4}$ confined in nanoporous silica and carbon scaffolds. Pore radii were varied from $8 \AA$ to $20 \mathrm{~nm}$, with increasing confinement effects observed with decreasing pore size. For similar pore sizes, the confinement effects were more pronounced for silica than for carbon scaffolds. The shift in the solid-solid phase transition temperature is much larger in silica than in carbon

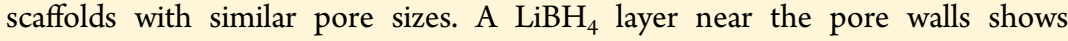
profoundly different phase behavior than crystalline $\mathrm{LiBH}_{4}$. This layer thickness was $1.94 \pm 0.13 \mathrm{~nm}$ for the silica and $1.41 \pm 0.16 \mathrm{~nm}$ for the carbon scaffolds.

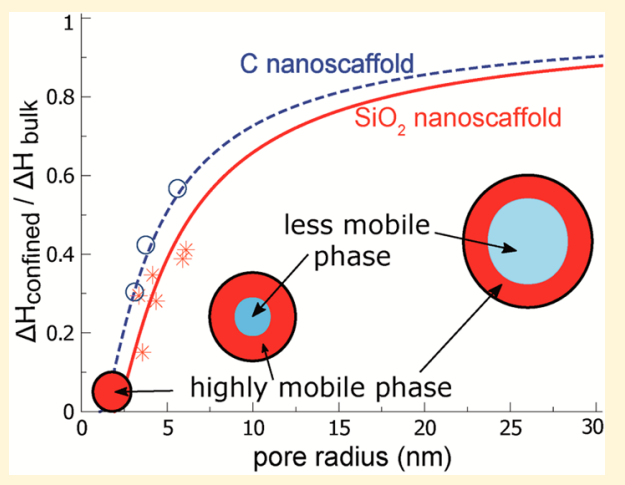
Quasi-elastic neutron scattering confirmed that the fraction of $\mathrm{LiBH}_{4}$ with high hydrogen mobility is larger for the silica than for the carbon nanoscaffold. These results clearly show that in addition to the pore size the chemical nature of the scaffold also plays a significant role in determining the hydrogen mobility and interfacial layer thickness in nanoconfined metal hydrides.

\section{INTRODUCTION}

Lithium borohydride is an ionic compound consisting of $\mathrm{Li}^{+}$ cations and $\left[\mathrm{BH}_{4}\right]^{-}$anions, which is of interest for energy storage and conversion. ${ }^{1-5}$ It contains $18.5 \mathrm{wt} \%$ hydrogen and thus is a promising material for solid-state hydrogen storage. ${ }^{1}$ However, the hydrogen is released above $673 \mathrm{~K}$ in multiple steps, whereas low hydrogen desorption temperatures and fast kinetics are required for integration with low-temperature fuel cells. At room temperature, crystalline $\mathrm{LiBH}_{4}$ has an orthorhombic structure. This low-temperature phase transforms to a hexagonal phase at about $383 \mathrm{~K}$. Interestingly, $\mathrm{Li}^{+}$ions in the hexagonal (high temperature) phase of $\mathrm{LiBH}_{4}$ are highly mobile, resulting in an ionic conductivity of $10^{-3} \mathrm{~S} / \mathrm{cm}$ at $390 \mathrm{~K}$; therefore, this material is also considered to be promising as a solid-state ionic conductor for $\mathrm{Li}$ ion batteries. ${ }^{4}$ However, for battery applications, high ionic conductivity at room temperature is required, and it has recently been shown that this might be achieved by partial anion substitution or nanoconfinement. ${ }^{5,6}$

It is well known that nanosized materials have physical and chemical properties different from those of the corresponding macrocrystalline materials. The special properties of nanomaterials originate from their high surface to volume ratio. ${ }^{7}$ For metal hydrides, the effects of nanosizing include a reduction of hydrogen diffusion distances and increased specific surface area so that the rate of hydrogen exchange is increased. To sustain the properties of nanoparticles, their growth under operating condition must be avoided, for instance, by confining the hydride nanoparticles in porous materials. These are usually carbon materials because of their chemical inertness and hightemperature stability. Carbon materials are also known to have a high thermal conductivity, which is beneficial for heat management during hydrogen cycling. On the other hand, oxidic porous materials such as silica are promising for confining $\mathrm{LiBH}_{4}$ for solid-state battery electrolytes, as low electronic conductivity is a prerequisite for electrolytes in all solid-state batteries. $^{5}$

For $\mathrm{LiBH}_{4}$, nanoconfinement improves the hydrogen sorption kinetics as well as reversibility. Vajo et al. ${ }^{3}$ reported that nanoconfined $\mathrm{LiBH}_{4}$ exhibits low activation energy for hydrogen desorption. Upon cycling, the confined phase has a higher hydrogen cycling efficiency than does nonconfined $\mathrm{LiBH}_{4}$. A study by Cahen et al., ${ }^{2}$ using SBA-15 templated

Received: December 30, 2016

Revised: February 2, 2017

Published: February 2, 2017 
Table 1. Textural Properties of the Porous Scaffolds and the $\mathrm{LiBH}_{4}$ and Porous Scaffold Nanocomposites

\begin{tabular}{|c|c|c|c|c|c|c|c|c|}
\hline & $r_{\mathrm{p}}$ & $V_{\mathrm{p}}^{a}$ & $V_{\text {micro }}{ }^{b}$ & $S_{\mathrm{BET}}$ & $\mathrm{LiBH}_{4}$ & $\mathrm{LiBH}_{4 \text { extra }}{ }^{c}$ & confined & fraction of pores filled \\
\hline sample & $\mathrm{nm}$ & $\mathrm{cm}^{3} / \mathrm{g}$ & $\mathrm{cm}^{3} / \mathrm{g}$ & $\mathrm{m}^{2} / \mathrm{g}$ & wt $\%$ & wt $\%$ & wt $\%$ & $\%$ \\
\hline $\mathrm{SiO}_{2}-3.3$ & 3.3 & 0.28 & 0.05 & 311 & 18.7 & 4.2 & 14.5 & 92 \\
\hline $\mathrm{SiO}_{2}-3.6$ & 3.6 & 0.37 & 0.08 & 406 & 13.2 & 0 & 13.2 & 70 \\
\hline $\mathrm{SiO}_{2}-4.2$ & 4.2 & 0.65 & 0.10 & 657 & 27 & 0.8 & 26.2 & 87 \\
\hline $\mathrm{SiO}_{2}-4.4$ & 4.4 & 0.62 & 0.09 & 625 & 23 & 0 & 23 & 80 \\
\hline $\mathrm{SiO}_{2}-5.9$ & 5.9 & 0.77 & 0.03 & 475 & 30 & 3.7 & 26.3 & 78 \\
\hline $\mathrm{SiO}_{2}-6.1$ & 6.1 & 0.77 & 0.04 & 500 & 38 & 15.2 & 22.8 & 67 \\
\hline C-3.1 & 3.1 & 0.53 & 0.17 & 612 & 27.8 & 2.9 & 24.9 & 98 \\
\hline C-3.8 & 3.8 & 0.59 & 0.17 & 571 & 17.8 & 0 & 17.8 & 67 \\
\hline C-5.6 & 5.6 & 0.77 & 0.16 & 560 & 22.3 & 0 & 22.3 & 69 \\
\hline C-20 & 20 & 1.37 & 0.19 & 592 & 37 & 0.2 & 36.8 & 77 \\
\hline
\end{tabular}

${ }^{a}$ Total pore volume measured at $p / p_{0}=0.95$ for silica scaffolds and at $p / p_{0}=0.99$ for carbon scaffolds. ${ }^{b}$ Microporous volume determined from the $\mathrm{t}$ plot ${ }^{c}$ Amount of $\mathrm{LiBH}_{4}$ outside the pores as measured by DSC and expressed as the weight percentage of the nanocomposites.

ordered porous carbon materials as scaffolds, shows that nanoconfined $\mathrm{LiBH}_{4}$ starts to release hydrogen at $473 \mathrm{~K}$ and desorbs about 3 wt \% hydrogen within $1.5 \mathrm{~h}$ at $573 \mathrm{~K}$, which is only 0.5 wt \% for macrocrystalline $\mathrm{LiBH}_{4}$.

Another important effect of nanoconfinement on $\mathrm{LiBH}_{4}$ is the increased $\left[\mathrm{BH}_{4}\right]^{-}$and $\mathrm{Li}^{+}$mobility. ${ }^{8}$ Ionic conduction reaches $0.1 \mathrm{mS} / \mathrm{cm}$ at room temperature for $\mathrm{LiBH}_{4}$ confined in silica materials, more than 3 orders of magnitude higher than for macrocrystalline $\mathrm{LiBH}_{4}{ }^{5}$ Nuclear magnetic resonance (NMR) measurements on carbon-confined $\mathrm{LiBH}_{4}$ by Shane et al. ${ }^{9}$ showed fast hydrogen mobility for the confined $\mathrm{LiBH}_{4}$. However, the NMR signal also showed two distinct fractions of $\mathrm{LiBH}_{4}$ : one with a significantly higher mobility and another with mobility close to that of bulk $\mathrm{LiBH}_{4}$. Quasielastic neutron scattering (QENS) confirmed that $\mathrm{LiBH}_{4}$ confined in carbon scaffolds comprises highly mobile $\left[\mathrm{BH}_{4}\right]^{-}$units. It was proposed that this could be related to the strain developed during the confinement procedure. ${ }^{10}$ A detailed QENS study by Verdal et al. ${ }^{11}$ identified the nature of the motion of the $\left[\mathrm{BH}_{4}\right]^{-}$units and showed two fractions of $\mathrm{LiBH}_{4}$ with different mobilities. The mobile fraction increased with decreasing pore size, leading to the proposal of a core-shell model with a mobile shell thickness of about $0.8-0.9 \mathrm{~nm}$ at $360 \mathrm{~K}$. Using differential scanning calorimetric (DSC) studies, Liu et al. showed that confinement in carbon pores lowers the solid-solid phase-transition temperature. $^{12,13}$ An NMR investigation by Verkuijlen et al. ${ }^{8}$ was, as far as we are aware, the first to study $\mathrm{LiBH}_{4}$ confined in mesoporous silica instead of carbon. It showed two distinctly different phases; a phase with high $\mathrm{Li}^{+}$and hydrogen mobility and another with $\mathrm{Li}^{+}$and hydrogen mobility that resembles that of macrocrystalline $\mathrm{LiBH}_{4}$.

Herein, we use ordered mesoporous silica and carbon scaffolds to systematically study the impact of pore size, pore geometry, and the chemical nature of scaffolds on confinement effects for nanoconfined $\mathrm{LiBH}_{4}$. By combining hydrogen dynamics studies with calorimetric analysis, we obtain quantitative information on the two different fractions of $\mathrm{LiBH}_{4}$ that exist in the nanocomposites. This study reveals that both the pore size and the nature of the scaffold have a significant influence on the confinement effects. The effects are more pronounced for $\mathrm{SiO}_{2}$ than for carbon materials with similar pore sizes and pore geometry.

\section{EXPERIMENTAL SECTION}

2.1. Sample Preparation and Characterization. Ordered mesoporous silica, SBA-15, with a 1D pore system was synthesized according to the procedure described by Zhao et al. ${ }^{14}$ using block copolymer pluronic P123 as a template and tetraethylorthosilicate as the silica source. Different pore sizes were obtained by changing the aging time and temperature during the hydrothermal treatment (overview in Table 1). The porous carbon materials were carbon aerogels that were synthesized through resorcinol-formaldehyde condensation catalyzed by sodium carbonate as described by Pekala et al. ${ }^{15}$ The pore size was tuned by changing the organic to water ratio during the gel synthesis.

Before melt infiltration with $\mathrm{LiBH}_{4}$, support porosity was measured with nitrogen physisorption performed at $77 \mathrm{~K}$ using a Micromeritics Tristar 3000. The total pore volume was derived from the absorption branch of the nitrogen isotherms at $p / p_{0}=$ 0.95. The pore size distributions of the $\mathrm{SiO}_{2}$ were calculated from the adsorption branch of the isotherm by the NL-DFT method using the cylindrical pore kernel. The values are derived from the peak of the pore size distribution. Typically for pore sizes $<7 \mathrm{~nm}$, the NL-DFT values are more accurate, and about 1 $\mathrm{nm}$ larger, than those obtained via the BJH analysis. ${ }^{12}$ The pore size distributions of carbon samples were calculated from the desorption branch using the $\mathrm{BJH}$ method with the carbon black STSA equation. The surface areas were calculated using the BET equation.

Melt infiltration ${ }^{16}$ was employed to confine $\mathrm{LiBH}_{4}$ in the porous scaffolds with loadings corresponding to full pore filling. The details of the melt infiltration procedure have been previously reported. ${ }^{17}$ The $\mathrm{SiO}_{2}$ scaffolds were dried prior to sample synthesis under an Ar flow at $473 \mathrm{~K}$ for at least $24 \mathrm{~h}$ to remove possible residual water. The carbon scaffolds were dried in a hydrogen flow at $873 \mathrm{~K}$ for $5 \mathrm{~h}$ to remove oxygen-containing groups and to subsequently passivate the resulting dangling bonds with hydrogen as well as to gasify the most reactive fraction of the carbon material. ${ }^{18}$

The preparation of nanocomposites requires good contact between $\mathrm{LiBH}_{4}$ and the scaffolds, and this was achieved by thoroughly mixing them at least for $10 \mathrm{~min}$. After that, the physical mixture was transferred into a graphite sample holder placed in a stainless steel autoclave and initially pressurized to 50 bar of $\mathrm{H}_{2}$. The pressure is important to prevent partial decomposition during heating. ${ }^{14}$ The mixture was heated at 5 $\mathrm{K} /$ min to $573 \mathrm{~K}$, which is slightly above the $\mathrm{LiBH}_{4}$ melting temperature, and remained at that temperature for $25 \mathrm{~min}$ to allow the melt infiltration of $\mathrm{LiBH}_{4}$ into the pores.

$\mathrm{X}$-ray diffraction patterns of the samples were recorded using a Bruker D8 Advance with Co K $\alpha$ radiation, $\lambda=1.78897 \AA$. The 
XRD samples were placed on an airtight sample holder to prevent sample oxidation. Microstructural analysis was performed using an FEI Tecnai 20 transmission electron microscope (TEM) with a field-emission gun operated at 200 $\mathrm{kV}$. The samples were deposited onto carbon holey copper grids (200 mesh) by dipping the grid in a ground powder. Typically, during the insertion of the sample holder into the microscope column, the sample was exposed to air for about 2-5 s.

2.2. Differential Scanning Calorimetry. Differential scanning calorimetric (DSC) measurements were performed with a high-pressure DSC from Mettler Toledo (HP-DSC1). The temperature and the heat flow were calibrated using certified gallium, indium, and zinc references. The nanocomposites $(10-20 \mathrm{mg}$ ) were placed in a $40 \mu \mathrm{L}$ hermetically sealed aluminum pan. The data were recorded while heating and cooling between 305 and $565 \mathrm{~K}$ at $5 \mathrm{~K} / \mathrm{min}$ and 20 bar of $\mathrm{H}_{2}$. Each measurement involved two to three cycles to check the sample stability and to verify the reproducibility. The thermograms were processed with STARe software to determine the transition temperatures and the enthalpies. The transition temperature is the extrapolated onset temperature, an intersection of the tangential line drawn through the point of maximum slope and the baseline. The enthalpy is determined from the integration of the phase-transition peak. The enthalpy data of the nanocomposites were compared to those of the macrocrystalline $\mathrm{LiBH}_{4}$ measured under the same conditions. The error in the measured temperature is less than $1^{\circ}$, and that of the measured enthalpy is in the range of $6-8 \% .^{5}$ To determine the confined fraction of $\mathrm{LiBH}_{4}$, the amount of crystalline, extraporous $\mathrm{LiBH}_{4}$ was measured by comparing the experimental enthalpy of the solid-solid phase transition at the bulk transition temperature for the nanocomposites with that of macrocrystalline $\mathrm{LiBH}_{4}$ measured under the same conditions. The amount of the confined phase is the total amount of $\mathrm{LiBH}_{4}$ in the sample minus the amount of crystalline and hence extraporous $\mathrm{LiBH}_{4}$. When the extraporous $\mathrm{LiBH}_{4}$ peak was not observed, all of the $\mathrm{LiBH}_{4}$ was assumed to be confined.

2.3. Quasielastic Neutron Scattering. Quasielastic neutron scattering (QENS) measurements were carried out using time-of-flight (TOF) neutron spectrometer FOCUS located at continuous spallation source SINQ at the Paul Scherrer Institute, Switzerland. ${ }^{19,20}$ Isotopically enriched ${ }^{11} \mathrm{~B}$ (99.5\%) samples (chemical purity 98\%), purchased from Katchem, were used to avoid the strong neutron absorption by ${ }^{10} \mathrm{~B}$, present in natural boron. The samples were loaded in lead-sealed, double-walled, hollow cylindrical containers. The diameter of the cylindrical container was $10 \mathrm{~mm}$, and the wall distance (i.e., the sample space) was $1 \mathrm{~mm}$. Incident neutrons were prepared with a wavelength of $\lambda_{i}=4 \AA$, corresponding to an incident energy of $E_{\mathrm{i}}=5.11 \mathrm{meV}$ and an incident velocity of $v_{\mathrm{I}}=989 \mathrm{~m} / \mathrm{s}$. The scattering intensity $I(2 \theta, t)$ is recorded as a function of scattering angle $2 \theta$ and time of flight $t$. Data reduction is carried out using data analysis and visualization environment $\mathrm{DAVE}^{21}$ to convert the instrument-specific $I(2 \theta, t)$ to the scattering function $S(Q \omega)$. Thereby, the scattering intensity is expressed as a function of the momentum transfer $\hbar Q=\hbar k_{\mathrm{i}}-\hbar k_{\mathrm{f}}$, where $k_{\mathrm{i}}$ and $k_{\mathrm{f}}$ are the incident and scattering wave vectors, and as a function of the energy transfer $\hbar \omega=E_{\mathrm{i}}-$ $E_{\mathrm{f}}$, where $E_{\mathrm{i}}$ and $E_{\mathrm{f}}$ are the incident and scattering neutron energies, respectively. Because of the large incoherent scattering cross section $\sigma_{\text {inc }}$ of hydrogen as compared to those of lithium, carbon, and boron, we attribute all scattering intensity to the incoherent scattering of hydrogen. Hence, the contributions of other species, coherent scattering, and multiphonon events are neglected. In bulk $\mathrm{LiBH}_{4}$, rapid reorientations of the $\left[\mathrm{BH}_{4}\right]^{-}$ anions are responsible for the quasi-elastic signal. At the instrumental settings used, the energy resolution defining the width of the elastic line equals $\Delta E=0.2 \mathrm{meV}$. Data acquisition and treatment were carried out as described earlier, ${ }^{10,22}$ and the spectra were binned in a range of $Q$ values of $0.5 \AA^{-1}<Q<2.5$ $\AA^{-1}$. The resulting QENS spectra were analyzed using general purpose curve-fitting utility PAN, following the procedure described in the previous publication. ${ }^{10}$

\section{RESULTS AND DISCUSSION}

3.1. Structural Properties. Table 1 gives an overview of the textural properties of the supports as well as the properties of the nanocomposites, including the loading and the amount of confined $\mathrm{LiBH}_{4}$ in each sample, i.e., the fraction of pores that was filled. We tuned the pore radii from 3.3 to $6.1 \mathrm{~nm}$ and from 3.1 to $20 \mathrm{~nm}$ for the silica and carbon materials, respectively. The ordered mesoporous silica SBA-15 materials comprise uniform parallel pores connected by intrawall porosity. The porosity of the carbon materials originates from interparticle space and is dominated by carbon particles of $5-10 \mathrm{~nm}$ in size, ${ }^{23}$ as confirmed by the transmission electron micrographs of these supports (Figure S1). The pore volumes of the supports are between 0.3 and $0.8 \mathrm{~cm}^{3} / \mathrm{g}$ for silica materials and between 0.53 and $1.37 \mathrm{~cm}^{3} / \mathrm{g}$ for the carbon scaffolds, and this enables us to make samples with confined $\mathrm{LiBH}_{4}$ loading ranging from 13.2 to 36 wt \% with $60-100 \%$ pore volumes filled with $\mathrm{LiBH}_{4}$. The high carbon pore filling $(>70 \%)$ is achieved by the proper mixing of $\mathrm{LiBH}_{4}$ and the scaffolds and by multiple melt infiltration (at least two sessions of melting and cooling under hydrogen pressure).

3.2. Size- and Interface-Dependent Hydrogen Dynamics. Neutron scattering is a powerful tool to study the dynamics of complex hydrides because of the incoherent neutron scattering cross-section of hydrogen. Therefore, the effects of pore size and the nature of the scaffold on the hydrogen dynamics of our nanoconfined $\mathrm{LiBH}_{4}$ were investigated using QENS. QENS probes the transfer of small amounts of energy compared to the neutron incident energy. These small energy transfers are caused by energy redistributions in the samples originating from atomic translations or rotations. The QENS spectra of the macrocrystalline (bulk) $\mathrm{LiBH}_{4}$ recorded between 300 and $500 \mathrm{~K}$ (Figure $1 \mathrm{~A})^{10}$ show that the patterns changed significantly above $380 \mathrm{~K}$. This is a clear indication of the structural phase transition of $\mathrm{LiBH}_{4}$ at this temperature. The low-temperature phase is characterized by a broad inelastic feature with distinct structure at around $1.5 \mathrm{~ms}$. The elastic line is clearly separated from the inelastic part of the spectrum by an intensity minimum, indicative of a low density of states at low energy transfers. Above the phase-transition temperature, the separation between the elastic and inelastic parts of the spectrum disappears and the inelastic part of the spectrum shows no distinct features. In the HT phase, the quasielastic component, seen as a broad background around the elastic line, broadens, and the intensity at the base of the elastic line drops with increasing temperature (with the arrow in Figure 1 pointing to this feature). 10,22

Figure 1B,C shows the time-of-flight patterns for $\mathrm{LiBH}_{4}$ confined in carbon and silica (SBA-15) scaffolds with pore radii of 5.6 and $5.9 \mathrm{~nm}$, respectively. Compared to macrocrystalline $\mathrm{LiBH}_{4}$, the broadening of the base of the elastic line is less pronounced. Also, the sudden shift of the spectra with 

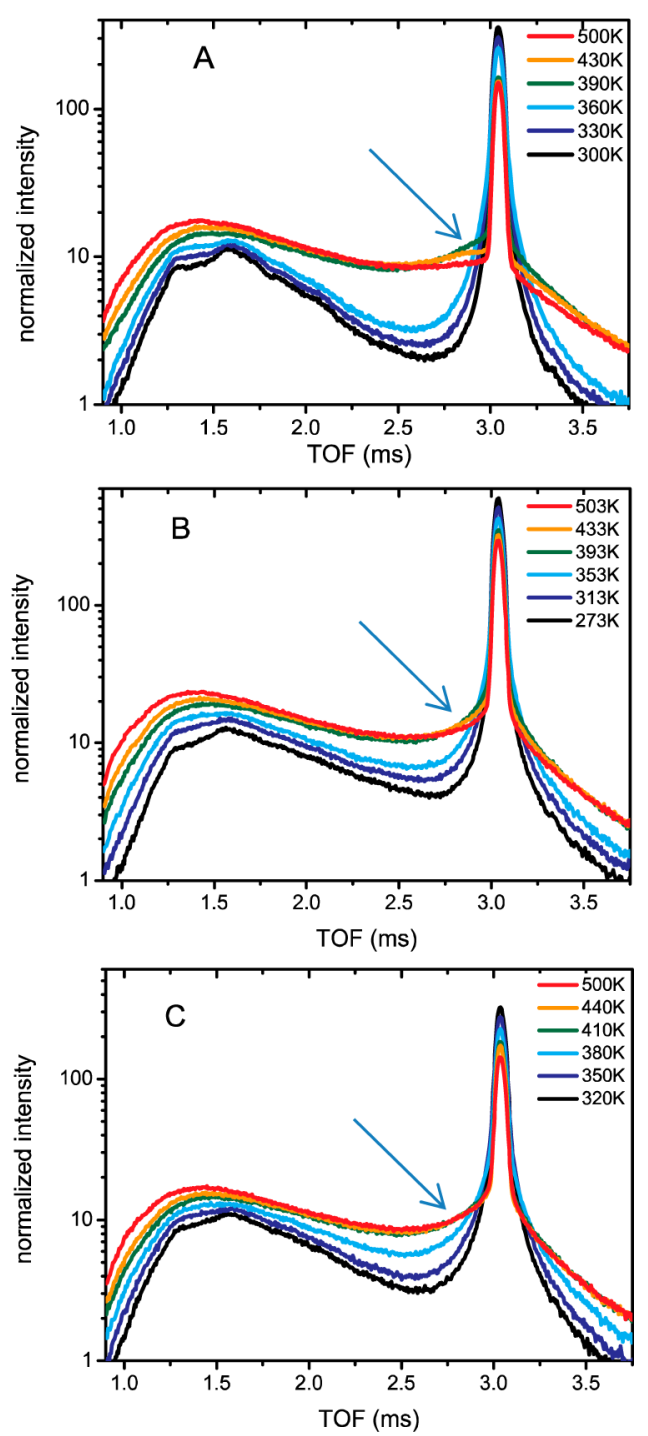

Figure 1. Time-of-flight spectra for bulk $\mathrm{LiBH}_{4}$ (A) and $\mathrm{LiBH}_{4}$ confined in carbon (B) and $\mathrm{SiO}_{2}$ (C) with pore radii of 5.6 and 5.9 $\mathrm{nm}$, respectively.

temperature, representative of the structural phase transition, is less apparent for the nanoconfined $\mathrm{LiBH}_{4}$, in line with previous results based on NMR. ${ }^{9}$ These results are also in line with previous QENS measurements that showed that the structural phase transition of $\mathrm{LiBH}_{4}$ was significantly suppressed when the compound was confined in high-surface-area nanoporous graphite (HSAG) with an average pore size of between 2 and $3 \mathrm{~nm}^{10}$

Even though, comparing the silica and carbon materials, the spectra look rather similar at first glance, small but distinct differences are present. In the case of the silica (Figure $1 \mathrm{C}$ ), all high-temperature spectra coincide at the base of the elastic line. In contrast, for the carbon case (Figure 1B) there is a clear temperature dependence of the quasielastic broadening, although it is less pronounced than for macrocrystalline $\mathrm{LiBH}_{4}$ (Figure 1A). Therefore, $\mathrm{LiBH}_{4}$ confined in carbon displays intermediate behavior between macrocrystalline $\mathrm{LiBH}_{4}$ and $\mathrm{LiBH}_{4}$ confined in $\mathrm{SiO}_{2}$. Because the materials have very similar pore sizes, we can conclude from these observations that silica materials exert stronger confinement effects on $\mathrm{LiBH}_{4}$ than do carbon scaffolds.
Figure 2A-C shows the time-of-flight spectra of a series of $\mathrm{LiBH}_{4} / \mathrm{SiO}_{2}$ nanocomposites with different pore sizes. A close
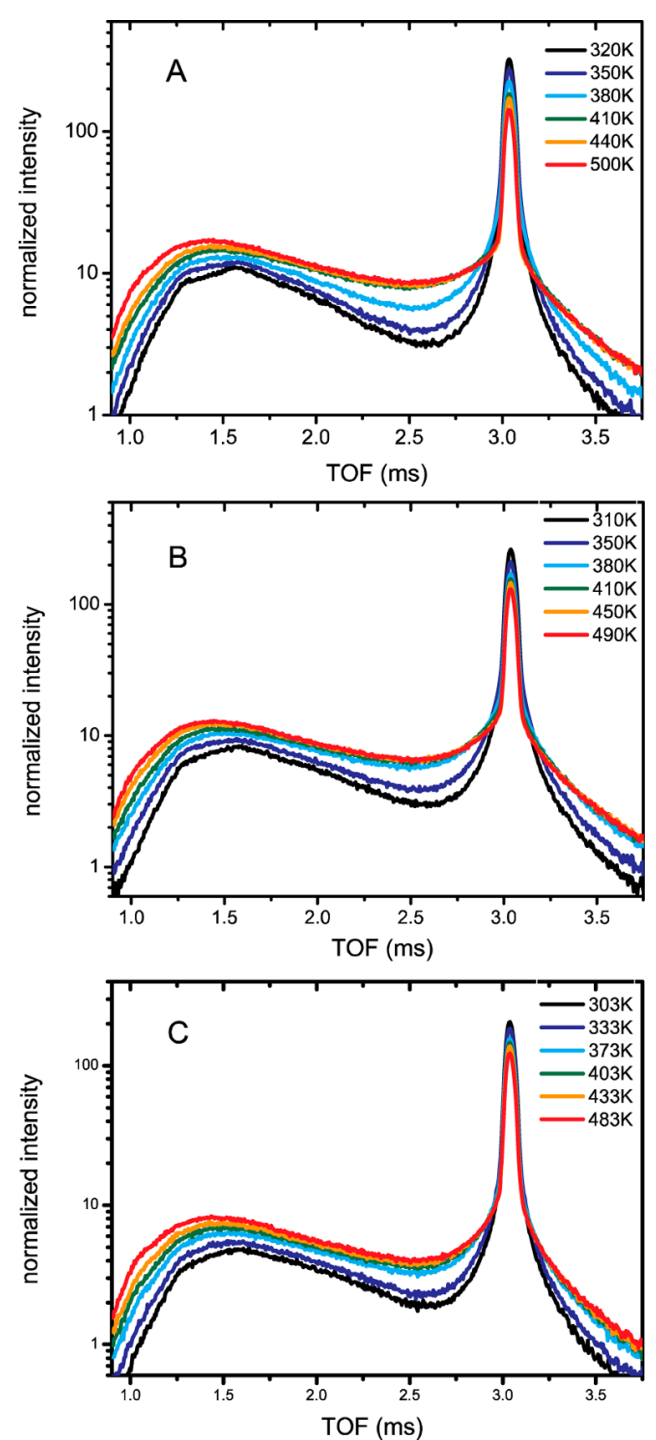

Figure 2. TOF spectra for $\mathrm{LiBH}_{4}$ confined in $\mathrm{SiO}_{2}$ with pore radii of (A) 5.9, (B) 4.4 , and (C) $3.6 \mathrm{~nm}$.

look at the spectra reveals that at high temperatures the signature of macrocrystalline $\mathrm{LiBH}_{4}$ is less pronounced for the smaller pore radii. The temperature at which the signature of the structural phase transition disappears decreases with decreasing $\mathrm{SiO}_{2}$ pore size: the TOF spectrum of $\mathrm{SiO}_{2}-5.9$ shows the signature of the high-temperature phase at $\geq 380 \mathrm{~K}$, whereas for $\mathrm{SiO}_{2}-4.4$ and $\mathrm{SiO}_{2}-3.6$, the highest temperatures at which it is observed are 350 and $333 \mathrm{~K}$, respectively. This means that the temperature at which the structural transition for nanoconfined $\mathrm{LiBH}_{4}$ occurs decreases with decreasing pore radius. Hence, the hydrogen dynamics of nanoconfined $\mathrm{LiBH}_{4}$ are also influenced by the pore size of the silica scaffold material.

The QENS results suggest the presence of at least two distinct fractions of $\mathrm{LiBH}_{4}$ in the silica scaffold; however, the present data do not allow us to unambiguously deconvolute the measured QENS spectra into two Lorentzian contributions. Hence, we modeled the spectra using an elastic peak of width $\Gamma_{\mathrm{el}}$ and an integrated area $I_{\mathrm{el}}$ and a single Lorentzian curve with a width $\Gamma_{\mathrm{qe}}$ and an integrated area $I_{\mathrm{qe}}$ for the quasi-elastic 
broadening. The width $\Gamma_{\mathrm{el}}$ of the elastic line was fixed to the width of the measured elastic line of a vanadium standard sample, corresponding to the instrumental resolution.

In macrocrystalline $\mathrm{LiBH}_{4}$, the phase transition is evidenced by a sudden change in the quasielastic broadening and a distinct change in activation energy between 360 and $390 \mathrm{~K}$. All quasielastic broadenings measured on the confined samples lie in between the data for macrocrystalline $\mathrm{LiBH}_{4}$. With decreasing pore size, the values deviate more and more from the bulk values. The deviation from the bulk behavior is larger for the carbon in the HT phase, whereas for the $\mathrm{SiO}_{2}$ it is larger in the LT phase. In other words, compared to carbon, $\mathrm{SiO}_{2}$ more strongly favors disordered, mobile, high-temperature-like behavior at room temperature. At low temperature, $\Gamma_{\mathrm{qe}}$ increases with decreasing pore size, indicative of increasing mobility due to confinement. The hydrogen mobility at low temperatures in the confined samples is much higher than for macrocrystalline $\mathrm{LiBH}_{4}$, and the smaller the pore sizes, the stronger the deviation from the bulk value.

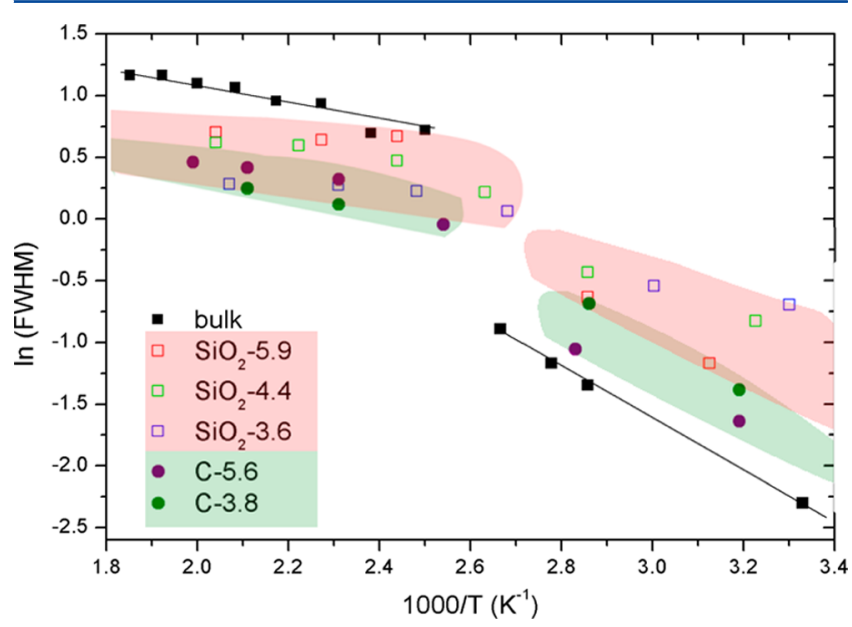

Figure 3. Temperature dependence of the quasielastic broadening for macrocrystalline $\mathrm{LiBH}_{4}$ and $\mathrm{LiBH}_{4}$ confined in $\mathrm{SiO}_{2}$ and carbon with different pore sizes.

3.3. Impact of Confinement on the Phase-Transition Temperature. The hydrogen mobility as measured by quasielastic neutron scattering shows clear differences between $\mathrm{LiBH}_{4}$ nanoconfined in $\mathrm{SiO}_{2}$ and in $\mathrm{C}$ matrices, indicating that the confinement effects are influenced by the chemical nature of the scaffold. A quantifiable aspect of confinement is the change in the thermodynamic stability and hence the phase-transition temperatures and enthalpies. Because the $\mathrm{LiBH}_{4}$ phase transitions involve a significant amount of enthalpy, calorimetry is a powerful option for investigating the phase-transition processes. Figure 4 illustrates DSC measurements of macrocrystalline $\mathrm{LiBH}_{4}$ and $\mathrm{LiBH}_{4}$ confined in $3.1 \mathrm{~nm}$ pores of a carbon matrix. During heating, the low-temperature solid phase transforms into a high-temperature phase with an onset temperature of $386 \mathrm{~K}$ for the macrocrystalline $\mathrm{LiBH}_{4}$. Further heating leads to the melting at $558 \mathrm{~K}$. During cooling, liquid $\mathrm{LiBH}_{4}$ starts to solidify at a slightly lower temperature than for melting.

For the confined $\mathrm{LiBH}_{4}$, the DSC shows two additional peaks; one below the solid-solid phase transition and the other below the melting temperature. If all $\mathrm{LiBH}_{4}$ is confined in the pores, then only the depressed peaks belonging to the confined phase

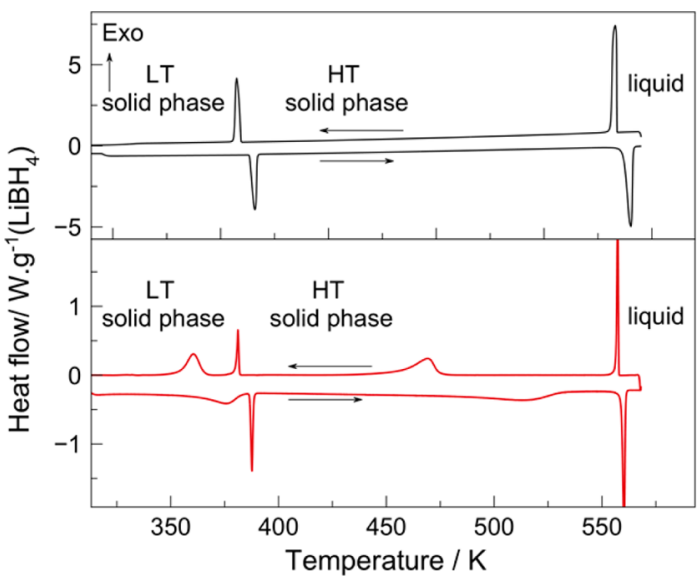

Figure 4. DSC thermograms of bulk $\mathrm{LiBH}_{4}$ (above) and the nanoconfined $\mathrm{LiBH}_{4}$ sample $\left(\mathrm{LiBH}_{4} / \mathrm{C}-3.1\right)$ (below).

were observed, as shown for some of the nanoconfined samples (e.g., samples $\mathrm{SiO}_{2}-4.4$ and C-3.8) in Figures 5A and 6A. The peaks of the confined phase are broadened, and the intensity of the peaks corresponding to features of the bulk is reduced. Another important point we found with DSC is that the phase transitions are fully reversible under hydrogen pressure; we found no indication of side reactions with either the carbon or the silica scaffolds. Table 2 gives an overview of the calorimetric results for $\mathrm{LiBH}_{4}$ confined in silica and carbon materials with different pore sizes. The table lists the onset temperatures, the depression in the phase transition, and the enthalpies of the solid-solid phase transition and melting. The onset temperatures and the enthalpies depend on the pore radius. The melting temperature is shifted more than $100^{\circ}$ down for $\mathrm{LiBH}_{4}$ confined in $3.3 \mathrm{~nm} \mathrm{SiO}$ pores.

The DSC thermograms of melting behavior of $\mathrm{LiBH}_{4} / \mathrm{SiO}_{2}$ and $\mathrm{LiBH}_{4} / \mathrm{C}$ are shown in Figure 5A. The size dependence of the melting temperatures was analyzed by plotting $\Delta T$ as a function of $1 / r$, as shown in Figure 5B. It can be seen that the melting-point depression is inversely proportional to the pore radius of both the $\mathrm{SiO}_{2}$ and $\mathrm{C}$ scaffolds.

It is generally accepted that a shift in melting temperature is related to size and interface effects, and it is typically ascribed to the increasing contribution of interfacial energy with decreasing size. $^{25-27}$ The relationship between the depressed melting temperature and the particle radius is often described by the Gibbs-Thomson relation, i.e., eq 1, where the ratio between the depressed temperature $(\Delta T)$ and the temperature of the bulk $\mathrm{LiBH}_{4}\left(T_{0}\right)$ scales with the interface energy $(\Delta \gamma)$ and inverse pore radius $\left(r_{\mathrm{p}}\right)$.

$$
\frac{\Delta T}{T_{0}}=\frac{2 \Delta \gamma V_{\mathrm{m}}}{\Delta H\left(r_{\mathrm{p}}-t\right)}
$$

In eq 1 , the enthalpy of the phase transition, $\Delta H$, is assumed to be independent of the particle size. This simplified description also assumes that the molar volume, $V_{\mathrm{m}}$ is the same for both phases involved in the transition. In some cases, the application of the Gibbs-Thomson relation requires a correction for an interfacial layer thickness, $t$, a fraction of the material that does not participate in the phase transition. For example, for ice melting in nanopores the layer thickness is on the order of 0.4 $\mathrm{nm}{ }^{28}$ To estimate interface energies from our experimental data, the observed temperature depressions were fitted using eq 1. Assuming no inert interfacial layer $(t=0)$, the resulting 


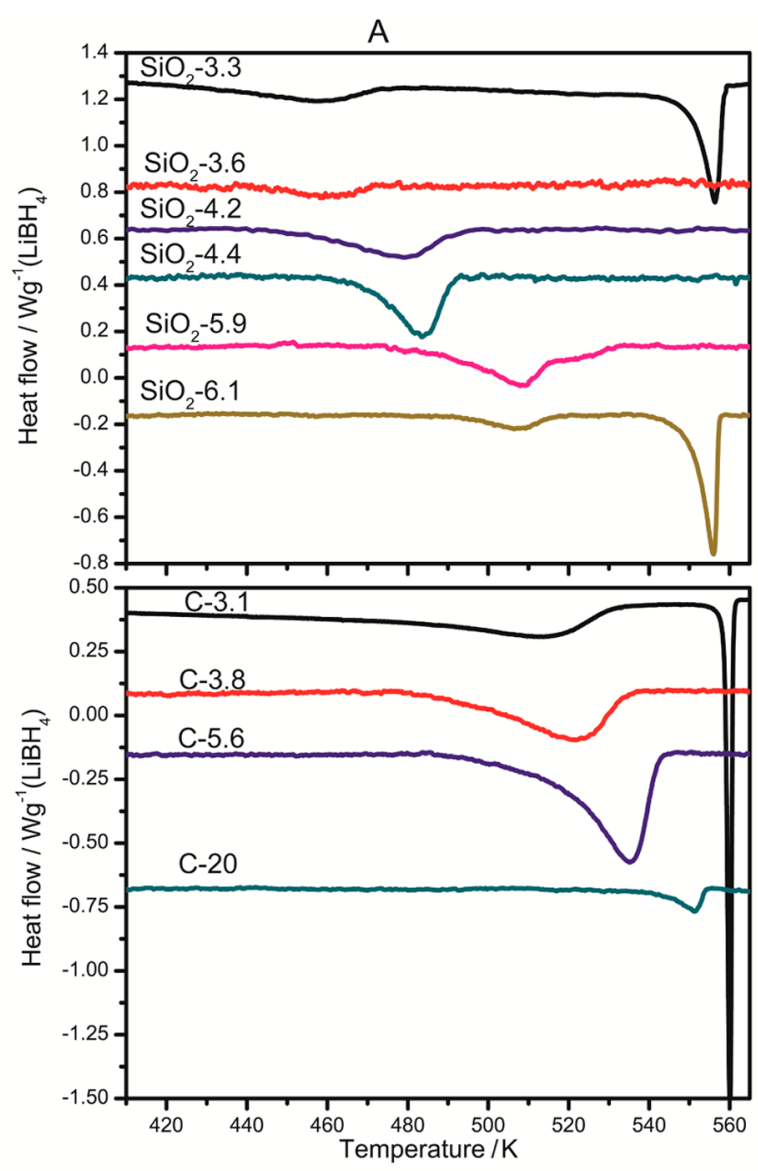

B

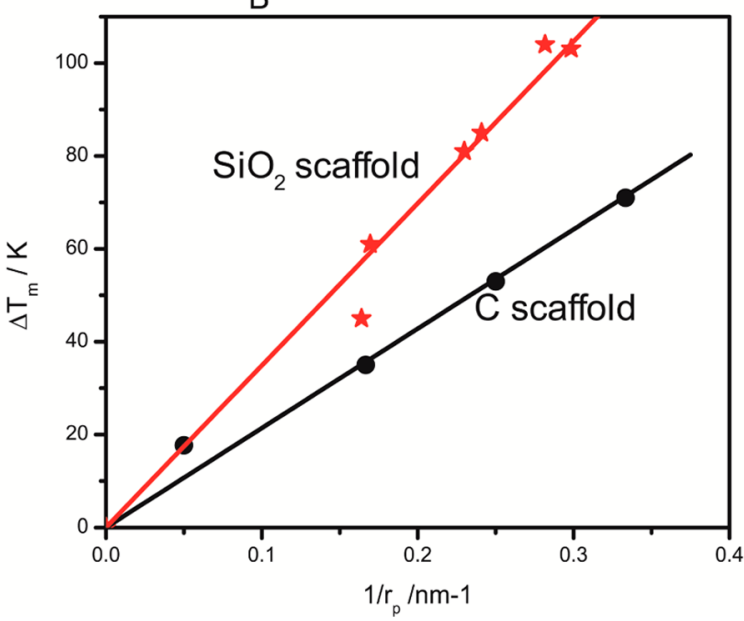

Figure 5. Melting-phase transition of nanoconfined $\mathrm{LiBH}_{4}$. (A) DSC thermograms of $\mathrm{LiBH}_{4} / \mathrm{SiO}_{2}$ (upper panel) and $\mathrm{LiBH}_{4} / \mathrm{C}$ (lower panel). (B) Temperature depression as a function of the inversed pore radius. Solid lines are a straight line fit. The bulk melts at $559 \mathrm{~K}$ and freezes at $558 \mathrm{~K}$.

interface energy is $0.018 \mathrm{~J} / \mathrm{m}^{2}$. If including an inert layer, the surface energy is $0.015 \mathrm{~J} / \mathrm{m}^{2}$ and $t$ is $0.6 \mathrm{~nm}$. This gives a first indication of the interfacial energy, but we show in the next section how the interfacial energy can be determined more accurately. It is interesting to observe that the calculated effective interfacial energy for the confined samples is about an order of magnitude lower than the surface energy of macrocrystalline $\mathrm{LiBH}_{4}, \sim 0.12 \mathrm{~J} / \mathrm{m} .{ }^{29,30}$ This points to a strong favorable interaction between the silica pore walls and the
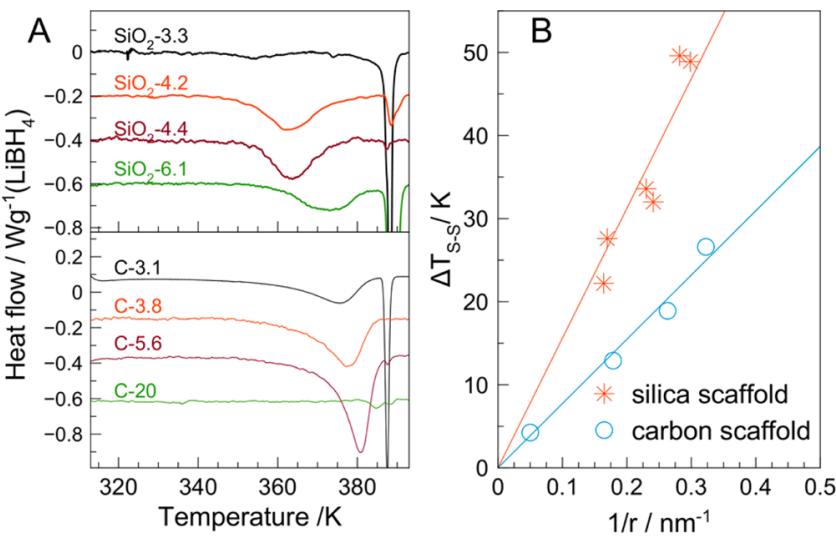

Figure 6. Solid-solid phase-transition temperatures of confined $\mathrm{LiBH}_{4}$ : (a) DSC thermograms of $\mathrm{LiBH}_{4} / \mathrm{SiO}_{2}$ during heating (upper) and $\mathrm{LiBH}_{4} / \mathrm{C}$ (lower). (b) Onset of the phase-transition temperature as a function of inverse pore radius (right). Solid lines are linear fits.

Table 2. Onset Temperature and Enthalpy for the SolidSolid Phase Transition and Depression in the Melting Temperature

\begin{tabular}{|c|c|c|c|c|c|}
\hline & $T_{\text {onset, solid-solid }}$ & $\Delta T_{\text {solid-solid }}$ & $\Delta H_{\text {solid-solid }}{ }^{a}$ & $\Delta T_{\mathrm{m}}$ & $\Delta H_{\mathrm{m}}{ }^{a}$ \\
\hline sample & $\mathrm{K}$ & $\mathrm{K}$ & $\mathrm{kJ} / \mathrm{mol}$ & $\mathrm{K}$ & $\mathrm{kJ} / \mathrm{mol}$ \\
\hline $\mathrm{SiO}_{2}-3.3$ & 337.7 & 48.9 & 1.29 & 103 & 1.54 \\
\hline $\mathrm{SiO}_{2}-3.6$ & 337.0 & 49.6 & 0.66 & 102 & 0 \\
\hline $\mathrm{SiO}_{2}-4.2$ & 354.7 & 32.0 & 1.52 & 85 & 1.79 \\
\hline $\mathrm{SiO}_{2}-4.4$ & 353.0 & 33.6 & 1.23 & 81 & 2.03 \\
\hline $\mathrm{SiO}_{2}-5.9$ & 359.0 & 27.6 & 1.70 & 61 & 1.12 \\
\hline $\mathrm{SiO}_{2}-6.1$ & 364.4 & 22.2 & 1.80 & 45 & 1.20 \\
\hline C-3.1 & 360.0 & 26.6 & 1.27 & 71 & 1.35 \\
\hline C-3.8 & 367.7 & 18.9 & 1.77 & 53 & 2.63 \\
\hline$C-5.6$ & 373.7 & 12.9 & 2.37 & 35 & 4.27 \\
\hline C-20 & 382.4 & 4.25 & 2.98 & 18 & 3.91 \\
\hline $\mathrm{mc} \mathrm{LiBH}_{4}{ }^{b}$ & 386.6 & 0 & 4.18 & 0 & 7.60 \\
\hline
\end{tabular}

${ }^{a}$ The enthalpies were calibrated using macrocrystalline $(\mathrm{mc}) \mathrm{LiBH}_{4}$ as a reference. ${ }^{b}$ Theoretical $\Delta H$ values were taken from the literature. ${ }^{24}$ The raw data measured values were 2.26 and $4.60 \mathrm{~kJ} / \mathrm{mol}$ for the solid-solid transition and melting, respectively

nanoconfined $\mathrm{LiBH}_{4}$, resulting in a much lower effective interfacial energy and hence a high stability of the confined $\mathrm{LiBH}_{4}$.

The impact of the size on the solid-solid phase-transition temperatures has never been investigated in detail, especially for silica scaffolds; hence, we did a detailed study on these effects for the carbon and silica materials. For $\mathrm{LiBH}_{4}$ confined in silica, the depression is largest for the smallest pore radius and up to $49^{\circ}$ for $\mathrm{SiO}_{2}$ with $3.3 \mathrm{~nm}$ pores (Figure 6A, upper frame). As can be seen in Figure 6A (lower frame), for carbon scaffolds the impact of pore size on the solid-solid depression is much smaller than for the silica scaffolds. For example, the depression was $49 \mathrm{~K}$ for $\mathrm{SiO}_{2}-3.3$ and only $27 \mathrm{~K}$ for $\mathrm{C}-3.1$ even though they have similar pore radii. The differences are clearly seen in Figure $6 \mathrm{~B}$ in which the phase-transition temperature shifts are plotted as a function of $1 / r$.

3.4. Comparing Silica and Carbon Scaffolds. In all cases, the measured enthalpy of the solid-solid phase transition of the confined phase (Table 2) decreases with decreasing pore size of the scaffold. Decreasing transition enthalpies of confined phases have also been observed for water, ${ }^{31}$ organic materials, ${ }^{32}$ and 

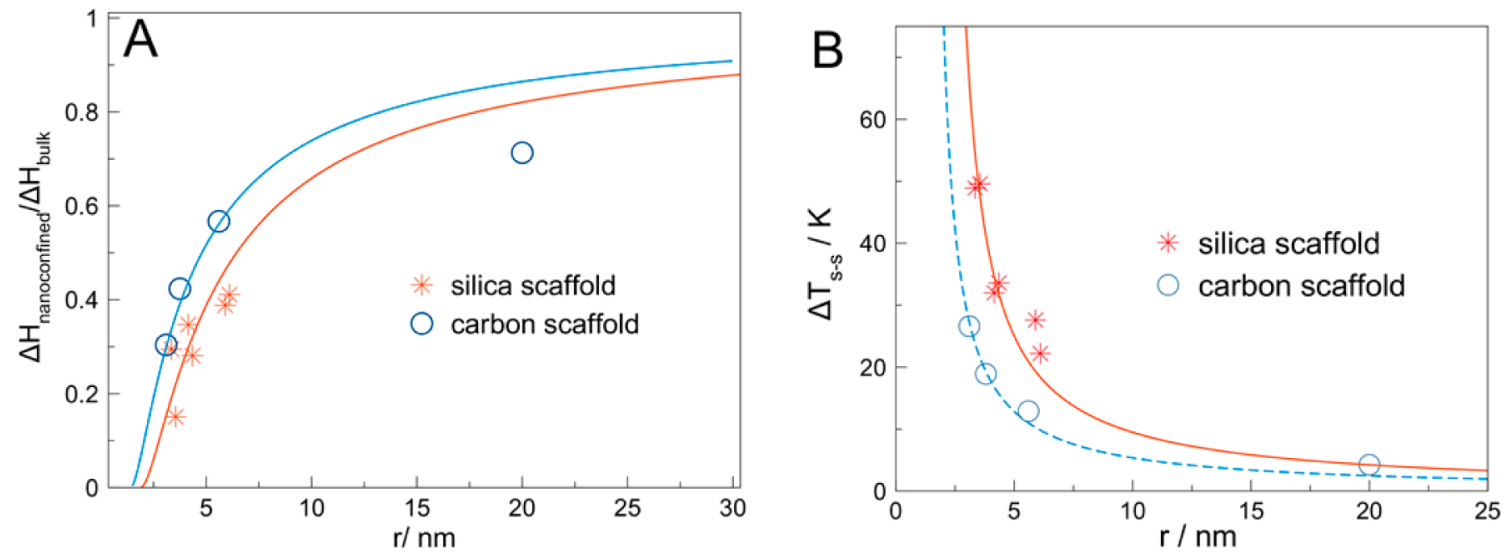

Figure 7. Size-dependence enthalpy and depression for the structural phase transition of nanoconfined $\mathrm{LiBH}_{4}$. (A) Relative enthalpy with the curves fitted using eq 2. (B) Depression of the solid-solid phase-transition temperatures and the fitted curves of the Gibbs-Thomson relation (eq 1).

metals. ${ }^{33}$ Figure 7 a shows the measured enthalpies normalized to that of the macrocrystalline $\mathrm{LiBH}_{4}$. If we assume a core-shell model such as that proposed by Verdal et al., ${ }^{11}$ namely, that the measured enthalpy is due to material in the core of the pores that undergoes a phase transition (and hence material close to the pore wall does not contribute) and cylindrical pore geometries, then the relative enthalpy dependence on the pore radius $\left(r_{\mathrm{p}}\right)$ can be expressed by eq 2 , where $t$ is the interfacial thickness.

$$
\frac{\Delta H_{\text {confined }}}{\Delta H_{\text {bulk }}}=\left(1-\frac{t}{r}\right)^{2}
$$

Fitting the data using eq 2 results in an interfacial layer thicknesses of $1.41 \pm 0.16$ and $1.94 \pm 0.13 \mathrm{~nm}$ for the carbon and silica scaffolds, respectively. For carbon-confined $\mathrm{LiBH}_{4}$, the value is larger than the $0.83-0.99 \mathrm{~nm}$ at $373 \mathrm{~K}$ estimated by Shane et al. ${ }^{9}$ The thicker interfacial layer for $\mathrm{LiBH}_{4} / \mathrm{SiO}_{2}$ indicates that the specific interaction of $\mathrm{LiBH}_{4}$ with $\mathrm{SiO}_{2}$ extends over longer distances than for $\mathrm{C}$. It is important to mention here that pore walls are not atomically flat. For instance, it is known from the work of Gommes et al. that the amplitude of surface corrugation of the silica (SBA 15) is 1.6 $\mathrm{nm},{ }^{34}$ which is close to the value of $1.94 \mathrm{~nm}$ observed for the $\mathrm{LiBH}_{4}$ interfacial layer. However, the specific surface area of carbon materials and hence the effective pore corrugation are even larger than those for silica with a similar pore size (Table 1). This strengthens the conclusion that the confinement effects inherently extend over longer distances in the case of silica than for carbon, as the difference in interfacial layer thickness cannot be attributed to pore corrugation effects.

Using those interfacial layer thicknesses determined from the above analysis, the effective interfacial energy differences for the two structural phases of $\mathrm{LiBH}_{4}$ confined in either $\mathrm{SiO}_{2}$ or $\mathrm{C}$ can accurately be determined and are summarized in Table 3. The

Table 3. Summary of the Interfacial Layer Thickness and the Interfacial Energy Differences between $\mathrm{LiBH}_{4} / \mathrm{SiO}_{2}$ and $\mathrm{LiBH}_{4} / \mathrm{C}$ Interfaces

\begin{tabular}{ccc}
\multicolumn{1}{c}{ system } & $t(\mathrm{~nm})$ & $\Delta \gamma\left(\mathrm{J} / \mathrm{m}^{2}\right)^{a}$ \\
$\mathrm{LiBH}_{4} / \mathrm{SiO}_{2}$ & $1.94 \pm 0.13$ & $0.053 \pm 0.003$ \\
$\mathrm{LiBH}_{4} / \mathrm{C}$ & $1.41 \pm 0.16$ & $0.033 \pm 0.002$
\end{tabular}

${ }^{a_{T}}$ The indicated error is the fitting error; the error in the DSC measurements is about $6-9 \%{ }^{5}$ interfacial energy difference for the $\mathrm{SiO}_{2} / \mathrm{LiBH}_{4}$ interface $(0.053$ $\left.\mathrm{J} / \mathrm{m}^{2}\right)$ is higher than for the $\mathrm{C} / \mathrm{LiBH}_{4}$ interface $\left(0.033 \mathrm{~J} / \mathrm{m}^{2}\right)$. This is most likely due to the different interaction between $\mathrm{LiBH}_{4}$ and the pore walls of the scaffold materials. The surface of silica is polar with a surface energy of about $0.260 \mathrm{~J} / \mathrm{m}^{2}, 35,36$ whereas the carbon surface is apolar with a low surface energy of $0.032 \mathrm{~J} / \mathrm{m}^{2},{ }^{36,37}$ and hence a stronger interaction with silica than with carbon might be expected. ${ }^{36}$

3.5. Comparing Carbon Scaffolds with Different Pore Size Distributions. Carbon aerogels have a broader pore size distribution than the ordered mesoporous silica (SBA-15). We therefore additionally measured the calorimetric properties of $\mathrm{LiBH}_{4}$ confined in ordered nanoporous carbon scaffolds possessing relatively narrow pore size distributions (Figure S3) to investigate whether the carbon pore structure and poresize distributions have a large influence on the confinement effects. Figure 8 shows the DSC thermograms of nanocomposites prepared with microporous carbon $(\sim 0.8 \mathrm{~nm}$ pore radius), ${ }^{38}$ CMK-3 ( $\sim 1.8 \mathrm{~nm}$ pore radius), ${ }^{39}$ and Kroll carbons (ca. $4.9 \mathrm{~nm}$ pore radius). ${ }^{40}$ For comparison, the thermograms of nanocomposites prepared with carbon aerogel and $\mathrm{SiO}_{2}(4.8$

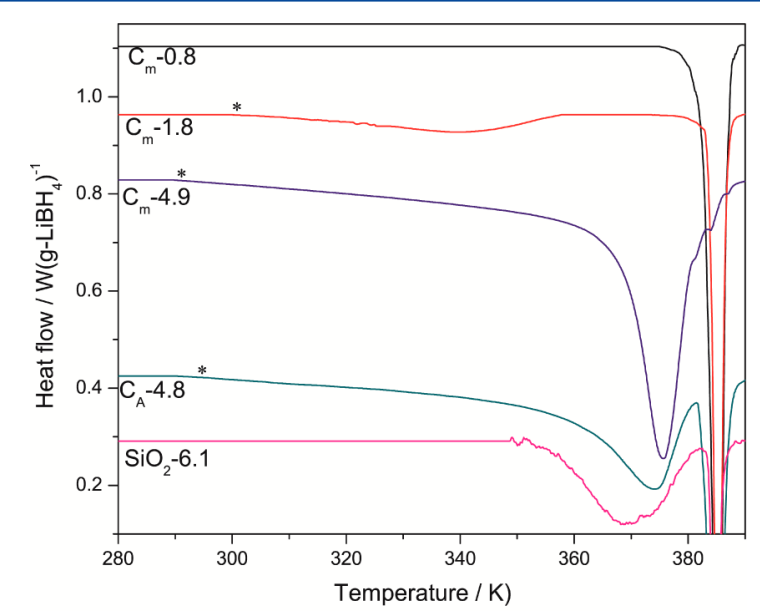

Figure 8. DSC thermograms for the solid-solid phase transition of $\mathrm{LiBH}_{4}$ confined in ordered nanoporous carbon $\left(\mathrm{C}_{\mathrm{m}}\right)$ with a pore radius as indicated (in $\mathrm{nm}$ ) on the figure. Thermograms of a nanocomposite prepared with carbon aerogel $\left(\mathrm{C}_{\mathrm{A}}\right)$ and SBA-15 $\left(\mathrm{SiO}_{2}\right)$ are also added for comparison. The asterisk $(*)$ indicates the onset temperature of the phase transition for the nanoconfined fractions. 
Table 4. Summary of the Properties and DSC Results for $\mathrm{LiBH}_{4}$ Confined in Ordered Nanoporous Carbon Scaffolds

\begin{tabular}{cccccccc} 
sample & $\mathrm{LiBH}_{4} / \mathrm{wt} \%$ & fraction confined $/ \%$ & $T_{\text {onset, solid-solid }} / \mathrm{K}$ & $\Delta T_{\text {solid-solid }} / \mathrm{K}$ & $T_{\text {peak }}$ & $\Delta H_{\text {solid-solid }} / \mathrm{kJ} / \mathrm{mol}$ & $t / \mathrm{nm}$ \\
$\mathrm{C}_{\mathrm{m}}-0.8$ & 30.8 & 82 & & & & & \\
$\mathrm{C}_{\mathrm{m}}-1.8$ & 49.2 & 84 & 301 & 77 & 340 & 0.36 \\
$\mathrm{C}_{\mathrm{m}}-4.9$ & 63.5 & 97 & 292 & 86 & 376 & 2.3 & 1.30 \\
\hline
\end{tabular}

and $6.1 \mathrm{~nm}$ pore radiui, respectively) are also included. Interestingly, only the peak corresponding to the structural phase transition for the unconfined (macrocrystalline) $\mathrm{LiBH}_{4}$ is observed in sample $\mathrm{C}_{\mathrm{m}}-0.8$ (prepared with microporous carbon). Note that about $82 \%$ of the $\mathrm{LiBH}_{4}$ in this sample is confined (Table 4). We attribute the absence of the structural phase transition for the confined fraction to the fact that the pore radius is below the interfacial layer thickness $(1.41 \pm 0.16$ $\mathrm{nm}$ ) determined for $\mathrm{LiBH}_{4}$ nanoconfined in carbon materials. Therefore, $\mathrm{LiBH}_{4}$ confined in carbon pores below this range is not expected to show any phase transition.

The onset temperatures for the structural phase transition for the confined fraction of $\mathrm{LiBH}_{4}$ in $\mathrm{C}_{\mathrm{m}}-1.8$ and $\mathrm{C}_{\mathrm{m}}-4.9$ are 301 and $292 \mathrm{~K}$, respectively, compared to about $378 \mathrm{~K}$ for macrocrystalline $\mathrm{LiBH}_{4}$. The slightly lower onset phase-transition temperature for $\mathrm{C}_{\mathrm{m}}-4.9$ is due to the presence of carbon with pores of less than $1.8 \mathrm{~nm}$ in radius. This also explains why the phase transition extends over a longer temperature range than that of $\mathrm{C}_{\mathrm{m}}-1.8$. However, the peak of the phase transition is clearly at a much higher temperature for $\mathrm{C}_{\mathrm{m}}-4.9$ than for $\mathrm{C}_{\mathrm{m}}-1.8$. These observations indicate that the pore size distributions of the scaffold are reflected in the peak width (broadness of the phasetransition event) whereas the average pore size of the scaffold determines the peak temperature of the phase transition. A clear proof of this is the fact that the DSC profile of $\mathrm{C}_{\mathrm{m}}-4.9$ is similar to that of the nanocomposite prepared with carbon aerogel with a similar average pore size $\left(\mathrm{C}_{\mathrm{A}}-4.8\right)$ and pore-size distributions but is much sharper because of the slight differences in pore size distributions (Figure S3). On the other hand, the peak temperatures for $\mathrm{C}_{\mathrm{m}}-4.9$ and $\mathrm{C}_{\mathrm{A}}-4.8$ are at even a slightly higher temperature than for $\mathrm{SiO}_{2}-6.1$ despite the fact that this silica has larger pores. These results confirm that the confinement effects are indeed more pronounced for $\mathrm{SiO}_{2}$ than for carbon. Another clear evidence comes from the fact that the nanocomposites prepared with the ordered mesoporous carbon materials have interfacial layer thicknesses (Table 4) that are very close to the average value determined for the samples prepared with carbon aerogel (Table 1). The interfacial layer thickness for these samples is estimated from eq 2 . The observed difference in the nanoconfinement effects is mainly due to the differences in the surface chemistry of the nanoscaffolds. Geometric differences might also play a role; SBA-15 has a more defined pore geometry (hexagonally packed cylindrical pores) than the ordered nanoporous carbon.

\section{CONCLUSIONS}

Quasielastic neutron scattering shows a clear impact of confinement on the hydrogen mobility, with the behavior of $\mathrm{LiBH}_{4}$ in carbon scaffolds being closer to that of macrocrystalline $\mathrm{LiBH}_{4}$ than when confining $\mathrm{LiBH}_{4}$ in silica scaffolds. The temperature of the solid-solid phase transition of $\mathrm{LiBH}_{4}$ is also depressed more strongly for silica than for carbon scaffolds and shifts from 387 to $338 \mathrm{~K}$ for $\mathrm{LiBH}_{4}$ confined in $3.3 \mathrm{~nm}$ silica pores. Pore-size-dependent enthalpy measurements confirm that there is a significant fraction of $\mathrm{LiBH}_{4}$ near the pore walls that does not undergo a structural phase transition, and assuming that this is a well-defined interfacial layer, we quantify its thickness as $1.94 \pm 0.13 \mathrm{~nm}$ for $\mathrm{SiO}_{2}$ and $1.41 \pm 0.16 \mathrm{~nm}$ for carbon scaffolds. If interpreting the shift of the phase transition in terms of the interfacial energy difference, the difference between the orthorhombic- and hexagonal-phase $\mathrm{LiBH}_{4}-\mathrm{SiO}_{2}$ interfaces is $0.053 \mathrm{~J} / \mathrm{m}^{2}$, whereas for the $\mathrm{LiBH}_{4}$-carbon interfaces this is only $0.033 \mathrm{~J} / \mathrm{m}^{2}$. Hence, we show a size dependence of the hydrogen dynamics and confinement energetics of $\mathrm{LiBH}_{4}$ on pore size as well as on the chemical nature of the scaffolds. This suggests that the nature of the scaffold and surface modification are important tools for tuning the hydrogen sorption and ion conduction properties of confined complex hydrides.

\section{ASSOCIATED CONTENT}

\section{S Supporting Information}

The Supporting Information is available free of charge on the ACS Publications website at DOI: 10.1021/acs.jpcc.6b13094.

Detailed preparation method for ordered nanoporous carbon, transmission electron micrographs, and pore size distribution of silica and carbon scaffolds. (PDF)

\section{AUTHOR INFORMATION}

\section{Corresponding Authors}

*E-mail: P.ngene@uu.nl. Phone: +31 22736379.

*E-mail: P.E.deJongh@uu.nl. Phone: +31 302531747

ORCID

Peter Ngene: 0000-0003-3691-0623

Jan Peter Embs: 0000-0002-2816-2875

Petra E. de Jongh: 0000-0002-2216-2620

Notes

The authors declare no competing financial interest.

\section{ACKNOWLEDGMENTS}

The authors thank R. van Zwienen for technical support with high-pressure equipment. This work was financially supported by a grant from a Dutch organization for scientific research (NWO ACTS sustainable hydrogen). A.R. and J.P.E. acknowledge financial support from the Swiss National Science Foundation (SNSF) by Sinergia project "Novel Ionic Conductors" under contract number CRSII2_160749/1. This experimental work is based on experiments performed at Swiss spallation neutron source SINQ Paul Scherrer Institute, Villigen, Switzerland.

\section{REFERENCES}

(1) Züttel, A.; Wenger, P.; Rentsch, S.; Sudan, P.; Mauron, P.; Emmenegger, $\mathrm{C}$. LiBH 4 a new hydrogen storage material. J. Power Sources 2003, 118, 1-7.

(2) Cahen, S.; Eymery, J.-B.; Janot, R.; Tarascon, J.-M. Improvement of the LiBH 4 hydrogen desorption by inclusion into mesoporous carbons. J. Power Sources 2009, 189, 902-908.

(3) Gross, A. F.; Vajo, J. J.; Van Atta, S. L.; Olson, G. L. Enhanced hydrogen storage kinetics of $\mathrm{LiBH} 4$ in nanoporous carbon scaffolds. $J$. Phys. Chem. C 2008, 112, 5651-5657. 
(4) Matsuo, M.; Nakamori, Y.; Orimo, S.-i.; Maekawa, H.; Takamura, $\mathrm{H}$. Lithium superionic conduction in lithium borohydride accompanied by structural transition. Appl. Phys. Lett. 2007, 91, 4103.

(5) Blanchard, D.; Nale, A.; Sveinbjörnsson, D.; Eggenhuisen, T. M.; Verkuijlen, M. H.; Vegge, T.; Kentgens, A. P.; de Jongh, P. E. Nanoconfined LiBH4 as a fast lithium ion conductor. Adv. Funct. Mater. 2015, 25, 184-192.

(6) Maekawa, H.; Matsuo, M.; Takamura, H.; Ando, M.; Noda, Y.; Karahashi, T.; Orimo, S.-i. Halide-stabilized LiBH4, a room-temperature lithium fast-ion conductor. J. Am. Chem. Soc. 2009, 131, 894-895.

(7) Roduner, E. Size matters: why nanomaterials are different. Chem. Soc. Rev. 2006, 35, 583-592.

(8) Verkuijlen, M. H.; Ngene, P.; de Kort, D. W.; Barre, C.; Nale, A.; van Eck, E. R.; van Bentum, P. J. M.; de Jongh, P. E.; Kentgens, A. P. Nanoconfined $\mathrm{LiBH} 4$ and enhanced mobility of $\mathrm{Li}+$ and $\mathrm{BH} 4-$ studied by solid-state NMR. J. Phys. Chem. C 2012, 116, 22169-22178.

(9) Shane, D. T.; Corey, R. L.; McIntosh, C.; Rayhel, L. H.; Bowman, R. C., Jr; Vajo, J. J.; Gross, A. F.; Conradi, M. S. LiBH4 in carbon aerogel nanoscaffolds: an NMR study of atomic motions. J. Phys. Chem. C 2010, 114, 4008-4014.

(10) Remhof, A.; Mauron, P.; Züttel, A.; Embs, J. P.; Łodziana, Z.; Ramirez-Cuesta, A.; Ngene, P.; de Jongh, P. Hydrogen dynamics in nanoconfined lithiumborohydride. J. Phys. Chem. C 2013, 117, 37893798.

(11) Verdal, N.; Udovic, T. J.; Rush, J. J.; Liu, X.; Majzoub, E. H.; Vajo, J. J.; Gross, A. F. Dynamical Perturbations of Tetrahydroborate Anions in $\mathrm{LiBH} 4$ due to Nanoconfinement in Controlled-Pore Carbon Scaffolds. J. Phys. Chem. C 2013, 117, 17983-17995.

(12) Liu, X.; Peaslee, D.; Jost, C. Z.; Baumann, T. F.; Majzoub, E. H. Systematic pore-size effects of nanoconfinement of LiBH4: elimination of diborane release and tunable behavior for hydrogen storage applications. Chem. Mater. 2011, 23, 1331-1336.

(13) Liu, X.; Peaslee, D.; Jost, C. Z.; Majzoub, E. H. Controlling the Decomposition Pathway of LiBH4 via Confinement in Highly Ordered Nanoporous Carbon. J. Phys. Chem. C 2010, 114, 14036-14041.

(14) Zhao, D.; Feng, J.; Huo, Q.; Melosh, N.; Fredrickson, G. H.; Chmelka, B. F.; Stucky, G. D. Triblock copolymer syntheses of mesoporous silica with periodic 50 to 300 angstrom pores. Science 1998, 279, 548-552.

(15) Pekala, R. Organic aerogels from the polycondensation of resorcinol with formaldehyde. J. Mater. Sci. 1989, 24, 3221-3227.

(16) de Jongh, P. E.; Eggenhuisen, T. M. Melt infiltration: an emerging technique for the preparation of novel functional nanostructured materials. Adv. Mater. 2013, 25, 6672-6690.

(17) Ngene, P.; Adelhelm, P.; Beale, A. M.; de Jong, K. P.; de Jongh, P. E. LiBH4/SBA-15 nanocomposites prepared by melt infiltration under hydrogen pressure: synthesis and hydrogen sorption properties. J. Phys. Chem. C 2010, 114, 6163-6168.

(18) Menendez, J. A.; Phillips, J.; Xia, B.; Radovic, L. R. On the modification and characterization of chemical surface properties of activated carbon: in the search of carbons with stable basic properties. Langmuir 1996, 12, 4404-4410.

(19) Janssen, S.; Mesot, J.; Holitzner, L.; Furrer, A.; Hempelmann, R. FOCUS: a hybrid TOF-spectrometer at SINQ. Phys. B 1997, 234-236, 1174-1176.

(20) Mesota, J.; Janssen, S.; Holitzner, L.; Hempelmann, R. FOCUS: Project of a space and time focussing time-of-flight spectrometer for cold neutrons at the Spallation Source SINQ of the Paul Scherrer Institute. J. Neutron Res. 1996, 3, 293-310.

(21) Azuah, R. T.; Kneller, L. R.; Qiu, Y.; Tregenna-Piggott, P. L.; Brown, C. M.; Copley, J. R.; Dimeo, R. M. DAVE: a comprehensive software suite for the reduction, visualization, and analysis of low energy neutron spectroscopic data. J. Res. Natl. Inst. Stand. Technol. 2009, 114, 341.

(22) Remhof, A.; Łodziana, Z.; Martelli, P.; Friedrichs, O.; Züttel, A.; Skripov, A. V.; Embs, J. P.; Strässle, T. Rotational motion of BH 4 units in $\mathrm{M} \mathrm{BH} 4(\mathrm{M}=\mathrm{Li}, \mathrm{Na}, \mathrm{K})$ from quasielastic neutron scattering and density functional calculations. Phys. Rev. B: Condens. Matter Mater. Phys. 2010, 81, 214304.
(23) Gavalda, S.; Gubbins, K.; Hanzawa, Y.; Kaneko, K.; Thomson, K. Nitrogen adsorption in carbon aerogels: A molecular simulation study. Langmuir 2002, 18, 2141-2151.

(24) Nakamori, Y.; Miwa, K.; Ninomiya, A.; Li, H.; Ohba, N.; Towata, S.-i.; Züttel, A.; Orimo, S.-i. Correlation between thermodynamical stabilities of metal borohydrides and cation electronegativites: Firstprinciples calculations and experiments. Phys. Rev. B: Condens. Matter Mater. Phys. 2006, 74, 045126.

(25) Faivre, C.; Bellet, D.; Dolino, G. Phase transitions of fluids confined in porous silicon: A differential calorimetry investigation. Eur. Phys. J. B 1999, 7, 19-36.

(26) Petrov, O.; Furo, I. Curvature-dependent metastability of the solid phase and the freezing-melting hysteresis in pores. Phys. Rev. E 2006, 73, 011608 .

(27) Unruh, K.; Huber, T.; Huber, C. Melting and freezing behavior of indium metal in porous glasses. Phys. Rev. B: Condens. Matter Mater. Phys. 1993, 48, 9021.

(28) Schreiber, A.; Ketelsen, I.; Findenegg, G. H. Melting and freezing of water in ordered mesoporous silica materials. Phys. Chem. Chem. Phys. 2001, 3, 1185-1195.

(29) Ge, Q. Structure and energetics of $\mathrm{LiBH} 4$ and its surfaces: a firstprinciples study. J. Phys. Chem. A 2004, 108, 8682-8690.

(30) Vajeeston, P.; Ravindran, P.; Fjellvåg, H. Nanostructures of LiBH4: a density-functional study. Nanotechnology 2009, 20, 275704.

(31) Jähnert, S.; Chavez, F. V.; Schaumann, G.; Schreiber, A.; Schönhoff, M.; Findenegg, G. Melting and freezing of water in cylindrical silica nanopores. Phys. Chem. Chem. Phys. 2008, 10, 60396051.

(32) Jackson, C. L.; McKenna, G. B. The melting behavior of organic materials confined in porous solids. J. Chem. Phys. 1990, 93, 90029011.

(33) Lai, S.; Guo, J.; Petrova, V.; Ramanath, G.; Allen, L. Sizedependent melting properties of small tin particles: nanocalorimetric measurements. Phys. Rev. Lett. 1996, 77, 99.

(34) Gommes, C. J.; Friedrich, H.; Wolters, M.; Jongh, P. E. d.; Jong, K. P. d. Quantitative characterization of pore corrugation in ordered mesoporous materials using image analysis of electron tomograms. Chem. Mater. 2009, 21, 1311-1317.

(35) Brunauer, S.; Kantro, D.; Weise, C. The surface energies of amorphous silica and hydrous amorphous silica. Can. J. Chem. 1956, 34, 1483-1496.

(36) Hazrati, E.; Brocks, G.; de Wijs, G. A. Carbon support effects on the hydrogen storage properties of $\mathrm{LiBH} 4$ nanoparticles: a firstprinciples study. J. Phys. Chem. C 2014, 118, 5102-5109.

(37) Eustathopoulos, N.; Nicholas, M. G.; Drevet, B. Wettability at High Temperatures; Elsevier: 1999; Vol. 3.

(38) Oschatz, M.; Leistner, M.; Nickel, W.; Kaskel, S. Advanced Structural Analysis of Nanoporous Materials by Thermal Response Measurements. Langmuir 2015, 31, 4040-4047.

(39) Jun, S.; Joo, S. H.; Ryoo, R.; Kruk, M.; Jaroniec, M.; Liu, Z.; Ohsuna, T.; Terasaki, O. Synthesis of New, Nanoporous Carbon with Hexagonally Ordered Mesostructure. J. Am. Chem. Soc. 2000, 122, 10712-10713.

(40) Oschatz, M.; Boukhalfa, S.; Nickel, W.; Lee, J.; Klosz, S.; Borchardt, L.; Eychmüller, A.; Yushin, G.; Kaskel, S. Kroll-carbons based on silica and alumina templates as high-rate electrode materials in electrochemical double-layer capacitors. J. Mater. Chem. A 2014, 2, 5131-5139. 